\title{
OPINIÃO DOS ALUNOS DE DIREITO DA USP
}

\section{Ana Lúcia Pastore Schritzmeyer *}

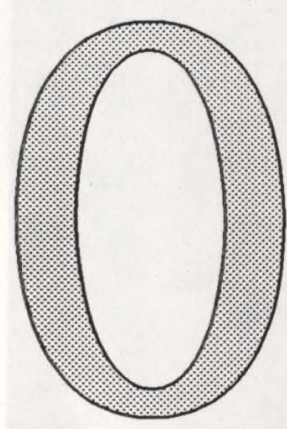

tema Pena de Morte, de Morte está muito próximo de nós, ao lado de muitas perpassando nossa esfera de atuações e outras complexas e de responsabilidades.

importantes questões, A idéia de realizar esta pesquisa suré um assunto que, de giu no início do curso Sociologia Jurídialgum modo e com ca: Métodos e Técnicas de Pesquisa, midiferentes intensida- nistrado por mim, durante 1991, e ofedes, chega até cada recido a 9 bolsistas do PET-CAPES um de nós, seja atra- Programa Especial de Treinamento da vés de noticiários, Coordenação de Pessoal de Nível Supede conversas ou rior, em convênio com o Departamento mesmo da constatação de que o falado de Filosofia e Teoria Geral do Direito é concreto, palpável e pode nos atingir da Universidade de São Paulo ${ }^{1}$. Como diretamente. Apesar da gravidade do parte das atividades didáticas desse curtema, no entanto, parece que com a so, solicitou-se aos bolsistas a elaboramesma força e intensidade com que ele ção individual de projetos de pesquisa nos atinge também nos abandona. Nes- que seriam desenvolvidos ao longo do se ir e vir de lucidez é provável que fi- ano. Como o tema Pena de Morte se requem, ao menos, algumas inquietações. petiu em vários projetos, o PET-CA-

A pesquisa apresentada neste artigo PES e o CEDISO - Centro de Estudos almeja não mais do que contribuir para Direito e Sociedade - decidiram apoiar o incremento dessas inquietações e não o desenvolvimento de um projeto únimenos do que afirmar que o tema Pena co, coletivo e de maior porte.

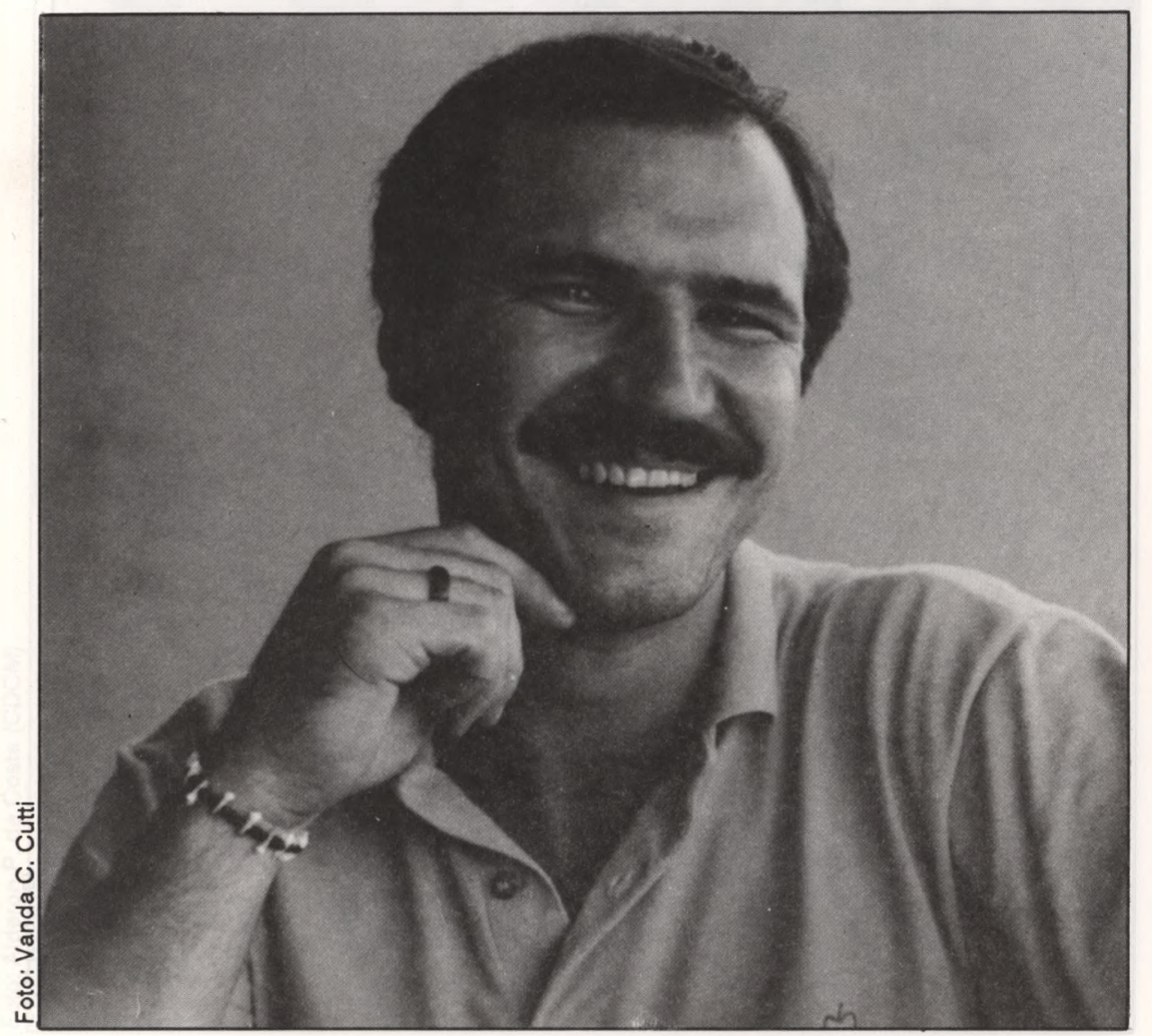

Fixou-se, então, como principal objetivo do trabalho avaliar a opinião de todos os alunos, regularmente matriculados no curso de graduação em Direito da USP, sobre a pena de morte e a constituicionalidade de um plebiscito a respeito de sua legalização no país. $O$ universo pesquisado, portanto, incluiu os 2.231 alunos matriculados, em agosto de 91 , nos 5 anos de graduação e nos 2 períodos letivos (matutino e noturno). Optou-se por trabalhar com uma amostra representativa de 400 desses 2.231 alunos, respeitando-se sua distribuição por sexo, período e ano de matrícula (a margem de erro foi de $4,5 \%$ ). O formulário de entrevista, basicamente elaborado pelos bolsistas, também foi por eles aplicado durante 3 manhãs e 3 noites (de 27 a 29/08/91), nos espaços internos de circulação da faculdade. $O$ trabalho prosseguiu com a análise dos dados e a elaboração de um relatório, concluído em novembro de $91^{2}$.

Antes da apresentação desses dados, porém, vale destacar alguns aspectos formais do trabalho que, provavelmente, são tão importantes quanto seu conteúdo. O primeiro, e mais significativo, é o fato dos entrevistados serem alunos de graduação em Direito da USP. Isto implica dizer que a opinião desse grupo não só revela um pouco da visão de mundo de universitários majoritariamente pertencentes a classes sócio-econômicas A - "alta" - e B - "média alta"3, como retrata pessoas cuja formação universitária poderá levá-las, num futuro próximo, a participarem do Poder Judiciário ou mesmo de quadros administrativos, políticos e acadêmicos de peso, Em outras palavras, é especialmente relevante saber a opinião desses alunos porque em suas prováveis atuações profissionais - como advogados, juízes, delegados de polícia, promotores, procuradores, etc. - estarão, direta ou indiretamente, lidando com o problema. Não bastasse isto, é relevante registrar que inserir no meio jurídicoacadêmico a prática da pesquisa empírica é uma iniciativa importante e, infe- 


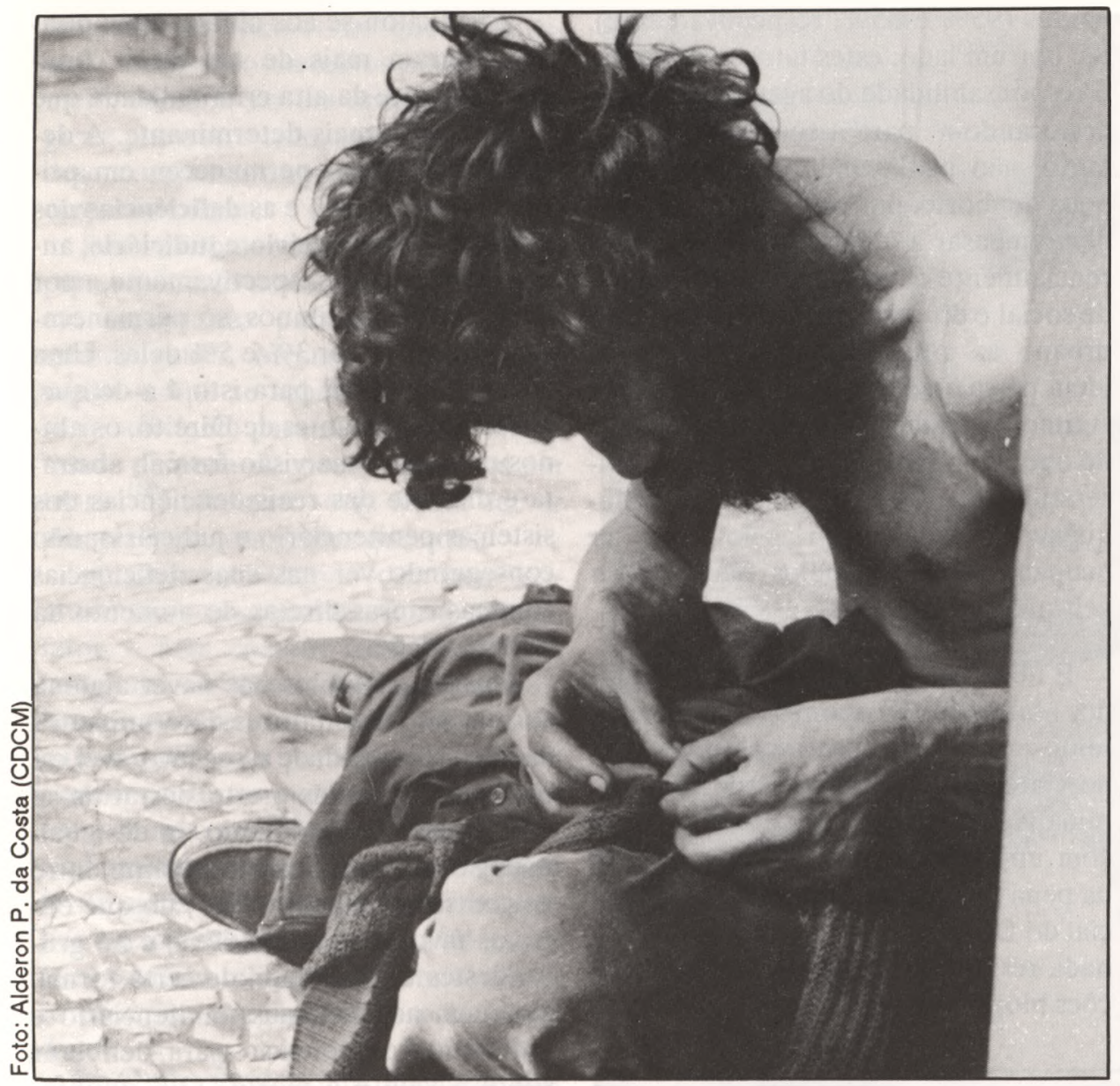

em que, num segundo turno de eleições presidenciais, teriam de escolher entre dois candidatos: um do PDS e outro do PT. Pouco mais da metade dos alunos (54\%) alegou que votaria no candidato do PT, $23 \%$ votariam no do PDS, $17 \%$ não votariam em nenhum deles (anulariam ou votariam em branco) e $6 \%$ deram outras respostas. Cruzando-se esta informação com a opinião sobre a pena de morte, percebemos que dentre os alunos favoráveis à pena, metade (50\%) votaria no PDS e $21 \%$ no PT, enquanto dentre os contrários mais da metade votaria no PT $(63 \%)$ e $16 \%$ no PDS. Pode-se afirmar, portanto, a existência de alguma similaridade entre a tendência política dos alunos e as posturas dos representantes destes partidos em relação à pena de morte, o que talvez indique o não esgotamento do canal político - partidário enquanto via de expressão de certos anseios dos eleitores. Contudo, é de se notar que mesmo dentre os que tenderiam a votar no PT existem os favoráveis à pena e dentre os que tenderiam a votar no PDS existem os contrários a ela.

lizmente, ainda incipiente no Brasil. Esta prática poderá contribuir para uma formação mais moderna do profissional de Direito, preparando-o para, com menos resistências e mais conhecimentos, relacionar-se com outros profissionais de áreas afins.

Um pouco, portanto, do que pensam e do que prometem ser profissionalmente os atuais alunos da FD-USP é o que aponta esta limitada investigação que, justamente por ser uma pesquisa de opinião, não permite aprofundamentos qualitativos. Tais aprofundamentos permitiriam, por exemplo, uma análise mais precisa de algumas oscilaçôes sutis entre grupos de alunos de diferentes faixas etárias, sexo, período e ano de matrícula, as quais não serão mencionadas neste artigo.

Iniciamos as entrevistas tentando verificar a existência de alguma correlação entre a tendência política dos alunos e sua opinião sobre a pena de morte. Pedimos, para tanto, que se posicionassem diante da hipotética situação

\section{LEGALIZAÇÃO DA PENA DE MORTE E TENDÊNCIA POLÍTICA Fonte : CEDI8O}

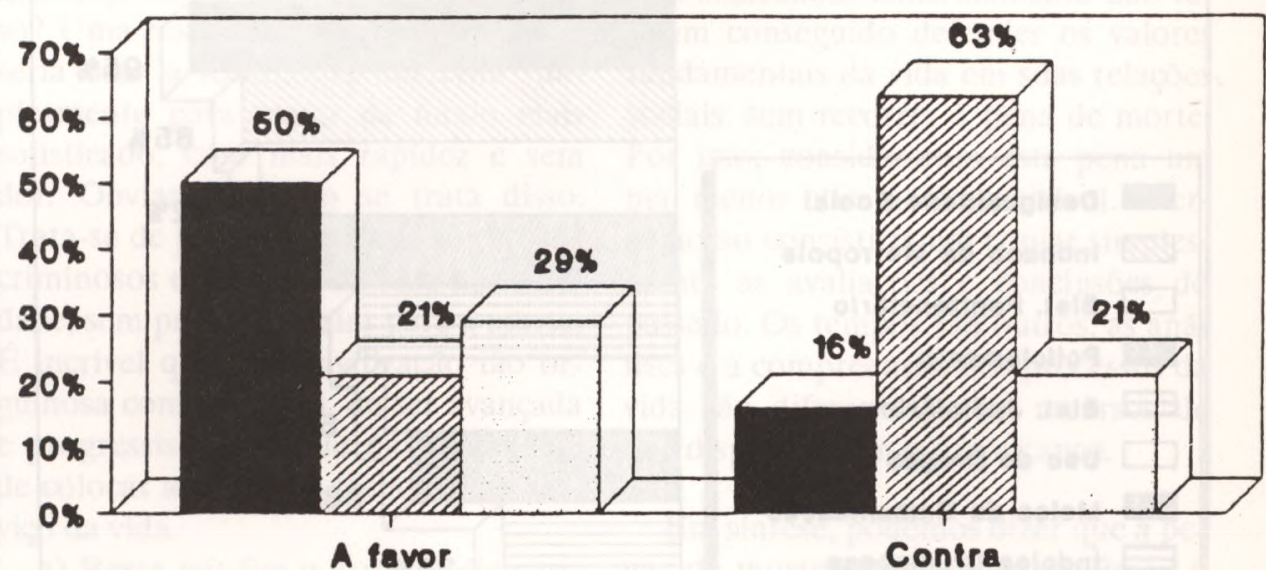

\section{PDS UIIST $\square$ Outras Respostas}

BASES : A favor (86), Contra (314) 
$\mathbf{N}$ orteados também pela hipotese de que se algum tipo de violência já houvesse ameaçado diretamente a vida dos alunos isto poderia influenciar a sua opinião sobre a pena de morte, perguntamos a eles se já haviam vivido alguma violência desse tipo. Quase 4 em cada $10(36 \%)$ responderam afirmativamente e dentre estes a maioria $(71 \%)$ declarou ter sido vítima de roubo. Além deste dado revelar um entrelaçamento dos bens vida e patrimônio, o que talvez se explique pelo já citado perfil sócio-econômico dos alunos (classes A e B), a hipótese levantada foi relativamente confirmada, pois dentre os favoráveis à pena verificou-se maior concentração de ameaçados (43\%) do que dentre os contrários a ela (34\%).

Outra hipótese que guiou as entrevistas foi a de que a visão dos alunos sobre os fatores determinantes do alto índice de criminalidade no município de São Paulo poderia se relacionar com a opinião sobre a pena de morte. Apuramos que quase a totalidade dos alunos considera a desigualdade social e o inchaço da metrópole fatores determi- nantes (95\% e $85 \%$, respectivamente). Se, por um lado, estes fatores suavizam a responsabilidade do agente, do crime, deslocando-a para a sociedade e, portanto, não justificando a aplicação da pena de morte, por outro lado, eles podem embasar a idéia de que são preferencialmente as vítimas da desigualdade social e do desordenado crescimento urbano as que mais delinqüem. Esta idéia passa ao largo da impunidade dos "crimes de colarinho branco" e do fato de que, num país como o Brasil, se miserabilidade fosse sinônimo de delinqüência, as penitenciárias deveriam ser ocupadas somente pelos não miseráveis/não delinqüentes.

É de se notar ainda que mais de $1 / 3$ dos alunos (35\%) apontou a índole criminosa de algumas pessoas como um dos fatores determinantes da alta criminalidade, visão esta incompatível com uma abordagem (re)socializadora da pena ou mesmo com uma função social do Direito, visto que nada ou quase nada restaria fazer frente à determinações biopsicológicas.

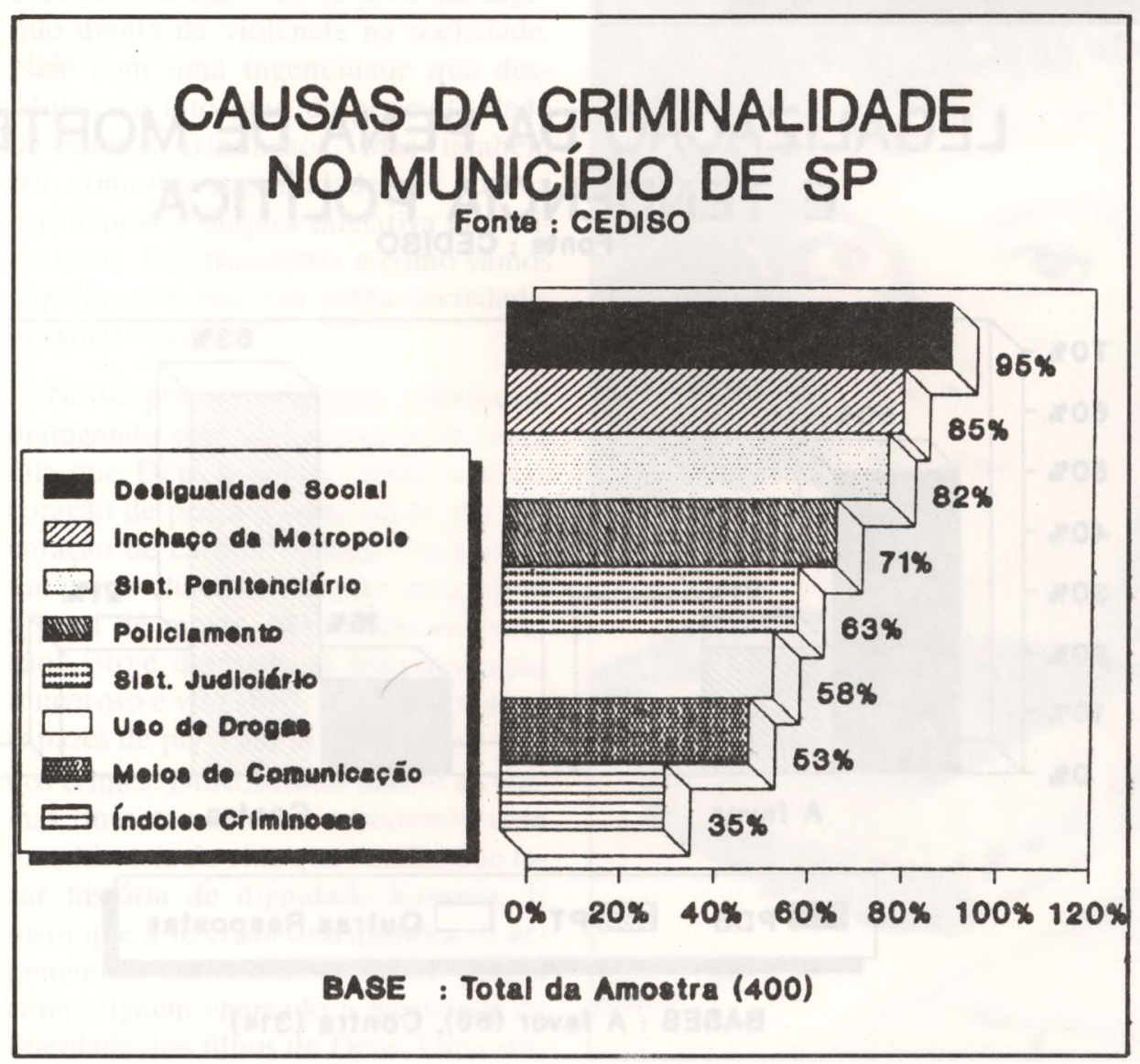

10 - Travessla • Malo/Agosio/92 
(63\%) seguidos de morte, além do homicídio doloso (58\%), estupro (34\%), seqüestro $(22 \%)$ e roubo $(8 \%)$ não seguidos de morte. Em outras pesquisas de opinião o estupro também foi o crime mais indicado. O que chama a atenção é a ênfase ao caráter retributivo/vingativo da pena, ou seja, segundo os alunos, crimes em que morre a vítima deve morrer o agente. Talvez, por detrás desta opinião, esteja a noção de que a pena tem, simultaneamente, efeitos "saneador" "preventivo": saneador ao "limpar da sociedade os maus e irrecuperáveis elementos" e preventivo ao exemplificar aos "potenciais delinqüentes" o que os aguarda. Estes efeitos, todavia, parecem não estar se verificando em países onde a pena de morte é aplicada. Estatísticas comprovam que a criminalidade não tem diminuído, por exemplo, no Texas, estado dos EUA em que a pena mais foi utilizada nos últimos 15 anos, sendo que, no mesmo país, no estado do Havaí, onde inexiste essa pena, o índice de criminalidade decresceu ${ }^{(6)}$.

As entrevistas terminaram com uma pergunta sobre a viabilidade constitucional de um plebiscito a partir do qual se deliberaria sobre a implantação da pena de morte no país. Surpreendentemente, mesmo entre alunos de Direito, a questão suscitou dúvidas: alguns sequer sabiam o que vem a ser um plebiscito e porque isto envolve a Constituição Federal. Embora isto possa revelar insuficiente conhecimento técnico-jurídico dos alunos, não se pode esquecer que o tema vem causando polêmicas nos meios jurídico-políticos, em geral. Tanto é assim que inclusive a emenda proposta pelo deputado federal Amaral Netto(PDS-RJ), sugerindo a introdução da pena de morte no art. $5^{\circ}$, inc. XLVII da Constituição Federal para casos de roubo, sequestro e estupro seguidos de morte, é considerada inconstitucional por uns e constitucional por outros. Na verdade, quanto ao plebiscito, inexiste, até o momento, lei que o diferencie do referendo e disponha sobre sua aplicação.

Apesar destas inconclusões, 1 em cada 3 alunos da Faculdade de Direito da USP considerou constitucional a realização de um plebiscito para se deliberar sobre a pena de morte no país. Percebemos, além disto, a existência de uma correlação entre ser favorável à pena e julgar o plebiscito constitucional, o que pode indicar uma tendência dos alunos a, apesar de não se sentirem em condições de analisar tecnicamente o assunto, avaliarem-no segundo juízos prévios de valor.

\section{CONSTITUCIONALIDADE DE UM PLEBISCITO Fonte : CEDISO}

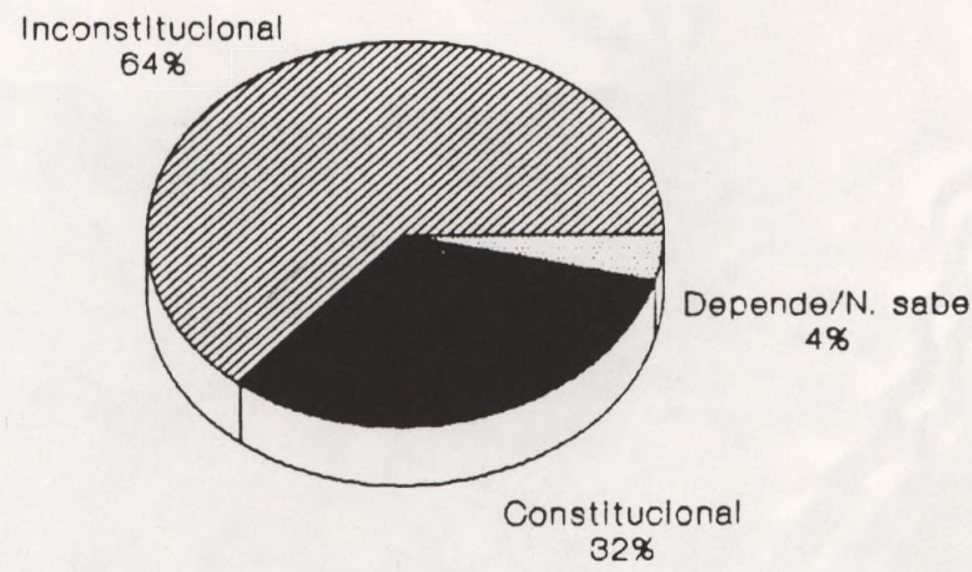

BASE : Total da Amostra (400)
T stes são os dados mais significativos do trabalho, restando, portanto, a partir deles, prosseguir com pesquisas junto, inclusive, a esse universo de alunos da USP. Fica a convicção de que o caminho para se discutir produtivamente qualquer tema, em especial aqueles cuja complexidade se assemelhe ao da peria de morte, passa, necessariamente, pelo levantamento minucioso do maior número de dados possível.

É sabido que a questão de ser favorável ou contrário à pena de morte, colocada nos limites em que o foi nesta pesquisa, pode gerar uma falsa polêmica, uma vez que sequer aborda o fato de, embora não termos essa pena legalmente prevista nos Códigos Penal e de Processo Penal, podermos verificar sua diária aplicação de forma totalmente alheia a qualquer controle democrático, pois restrita a critérios de grupos localizados e cujos interesses são oscilantes e tendenciosos. Este é um debate fulcral, pois ele traz à tona o chamado "dilema brasileiro" ${ }^{(7)}$, ou seja, a constatação de que vivemos numa sociedade em que as leis impessoais e universais, válidas, a princípio, indiferentemente para todos, esbarram, constantemente, nas hierarquias e jogos de favores pessoais que transformam Homems em homens e mulheres, brancos e negros, ricos e pobres, sulistas e nordestinos, doutores e analfabetos...

O problema não reside na constatação das diferenças: elas existem e, em alguns casos, devem até ser resguardadas. O desafio é o que fazer com estas constatações e como saber se elas são devidamente aquilatadas.

O que fazer com a constatação de que "Todos são iguais perante a lei, sem distinção de qualquer natureza. (...)" - art. $5^{\circ}$, caput - Constituição Federal - mas perceber que $o$ acesso à Justiça, à Educação, a Saúde, à Moradia e a muito mais é crivado por toda sorte de distinções: economicas, raciais, religiosas, políticas etc?

A pesquisa que realizamos não toca nestas sensibilidades anestesiadas por 
nossos medos e impotências, mas é um caminho para despertá-las e fazer com que continuemos pensando. $\mathrm{O}$ debate sobre a Pena de Morte nos alerta para o longo trajeto que ainda está por ser construído e que aponta para a árdua e imprescindível conquista da Cidadania.

* Ana Lúcia Pastore Schritzmeyer:Diretora do CEDISO - Centro de Estudos Direito e Sociedade Faculdade de Direito da Universidade de São Paulo

\section{NOTAS}

(1) Este Programa da CAPES - atualmente desenvolvido em mais de 40 instituiçōes de ensino superior e envolvendo quase 900 alunos de vários cursos de graduação por todo o país - abre um espaço que, ná FD-USP, sob a tutoria de José Eduardo Faria - Diretor-Presidente do CEDISO e professor do Departamento de Filosofia e Teoria Geral do Direito - vem sendo utilizado para o reforço e aprimoramento da formação teórica dos bolsistas e para sua iniciação em pesquisas sociológico-jurídicas.

(2) Equipe de Pesquisadores (bolsistas $2^{\circ}$ ano de graduaçáo): Andréa Hafez, Débora Regina Pupo, Dora Marzo de Albuquerque Cavalcante, Ivan Moreira, Luciana Salles Worms, Maria Emiliana Egydio de Carvalho, Marina Benevides Soares, Rogério Podkolinski Pasqua e Tatiana Cymbalista.

Coordenadoras do Campo e da Crítica (bolsistas $-3^{\circ}$ ano de graduação): Kathia Regina Martin e Monica Hernandes de Sảo Pedro.

Digitação dos Formulários no Banco de Dados: Rita de Cássia Barros Dias.

Programação e Tratamento Estatístico: José Reinaldo Riscal

(3) Relatórios de Classificaçâo SócioEconômica dos Matriculados na USP preparados pela FUVEST, desde 1974.

(4) Pesquisa DATAFOLHA, Folha de S. Paulo (Caderno Brasil), 20/09/91, p. 10.

(5) O Estado de S. Paulo, 25/08/91, p. 46.

(6) Folha de S. Paulo (Caderno Mundo), 12/08/91, p. 2.

(7) Roberto da Matta - Carnavais, Malandros e Heróis - Para uma Sociologia do Dilema Brasileiro. ( $4^{\mathrm{a}} \mathrm{ed}$.), Rio de Janeiro: Zahar, 1983.

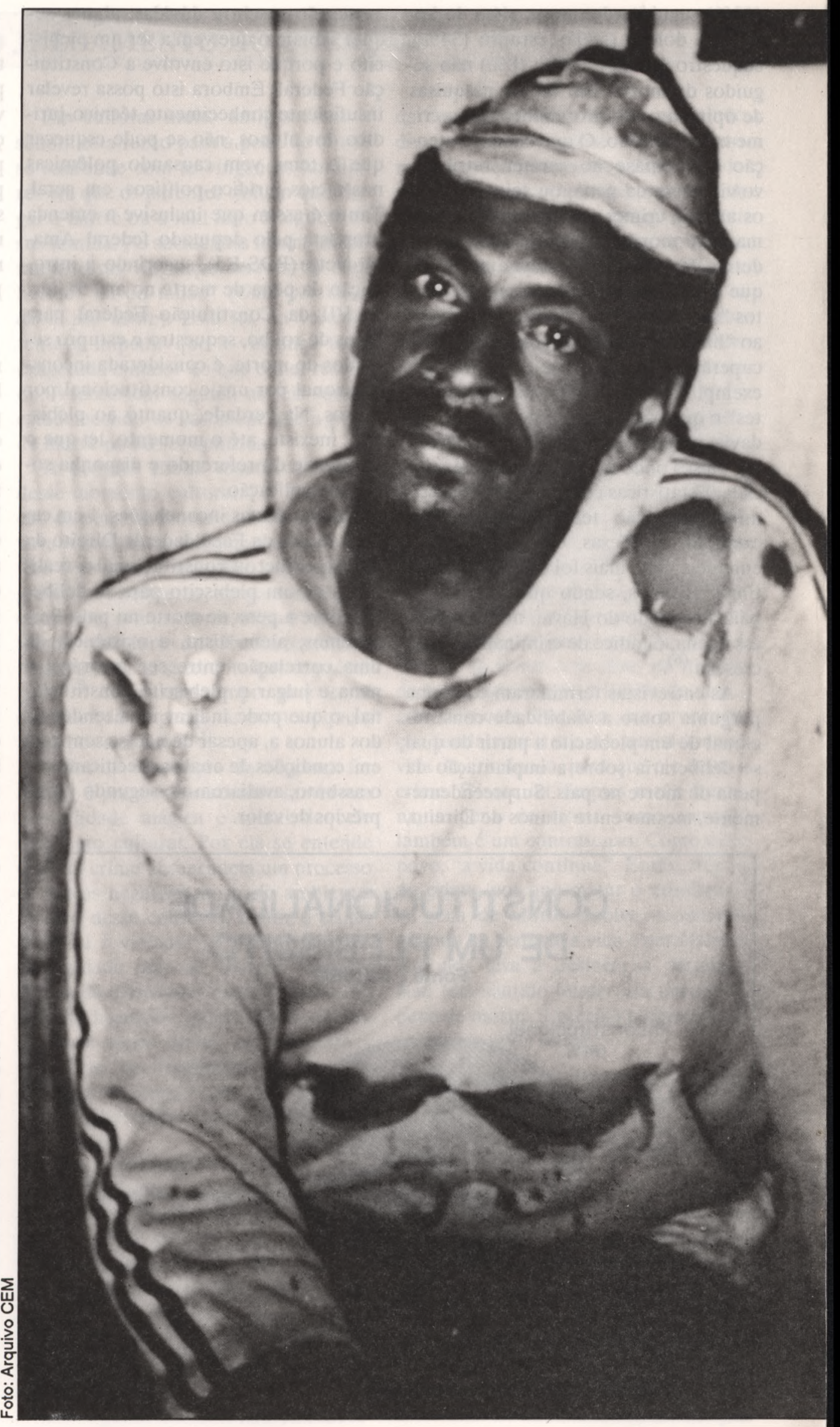

